\title{
Investigation of Metal Air-Cooling Process as an Element of Thermal Processing
}

\author{
Biryukov A.B. *, Gnitiev P.A. \\ Department of Technical Thermophysics, Donetsk National Technical University, Donetsk, Donetsk Region, Ukraine \\ *Correspondence: birukov.ttf@gmail.com
}

\begin{abstract}
Background: Nowadays on metal tempering and annealing its air cooling (AC) is realized inside furnace with forced coolant delivery. Scientific tools lack for metal AC study and design is substantiated. The aim of this work is to investigate technological and design furnace parameters influence on metal AC duration, as well as disclosure of metal AC heat engineering regularities. Materials and method: For study mathematical model of metal AC is used. It bases on solving the differential non-stationary heat conductivity equation in one-dimensional form for cylindrical ingots and lining. Results: For three lining design types and different technological parameters operation acceleration possibility due to lining design change was studied. It is found that with ceramic fibers on walls and roof acceleration is $31-45 \%$ and with all lining made of ceramic fiber it is $44-52 \%$ as compared with fireclay brick lining. For a furnace with hearth of fireclay bricks and ceramic fiber on the walls and roof, convective component varies from 10 to $30 \%$; for lining completely consisting of ceramic fibers it is $10-25 \%$. When using fireclay brick lining parts their inner temperature is higher than for ceramic fiber up to $50{ }^{\circ} \mathrm{C}$. Conclusions: Significant furnace lining materials type influence on metal AC intensity is proved. Heat removal mechanism on metal AC in furnace is disclosed, by establishing heat proportion directly removed from metal by convection. It is found that radiant heat transfer between metal and fireclay brick part of lining goes less intensively than with ceramic fiber part.
\end{abstract}

Keywords: Air-cooling process; furnace; convective heat exchange; radiant heat exchange; mathematical modeling; ceramic fiber lining

Received: Apr 6, 2019 Accepted: May 14, 2019 Online: May 27, 2019

\section{Introduction}

In conditions of increasing competition rate in the market of metallurgical and engineering products, there is a need in constant work on improving the quality of products on one hand, and reducing amount of resources consumed for their production, on the other.

One of the main roles in management of steel products quality is metal thermal processing, in many types of which (normalization, annealing) an important place is occupied by the processes of air-cooling (AC). Nowadays, AC process on thermal processing of steel products is carried out in furnaces, which imposes a number of requirements on this process, such as ensuring specified cooling speed or shortening the cooling time. Today the approaches to calculating these parameters are imperfect. This entails an over expenditure of energy resources and an increase in material residence time in the furnace due to insufficient study of the influence of various design and technological parameters on the process of heat removal from the metal. The creation of new furnaces and the reconstruction of existing ones require scientifically based methods for calculating rational parameters and optimizing the technical and economic characteristics of the process. The choice of rational air consumption is hampered by insufficient study of the cooling process in real conditions, the lack of sufficiently simple and reliable methods for its design calculation, etc. To meet the requirements, it is necessary to develop methods for engineering calculation of the process, mathematical models for determining the thermal state of the metal, the system of diagnostics and control.

Copyright (C) 2019 Biryukov A.B. and Gnitiev P.A. This is an Open Access article distributed under the terms of the Creative Commons AttributionNonCommercial 4.0 International License (http://creativecommons.org/licenses/by-nc/4.0/), permitting all non-commercial use, distribution, and reproduction in any medium, provided the original work is properly cited. 
Various methods for realizing the operation of metal cooling, from slow cooling in the furnace without coolant supply, to rapid cooling in liquids have been analyzed in [1]. The paper [2] shows the place of metal AC operations in the implementation of tempering and annealing. It is substantiated that failure to comply with the required AC rate may lead to a change in the structure of the metal in the annealing and normalization operations, as well as the preservation of residual stresses in the metal. The evolution of the AC operations is illustrated in [2]: from cooling of ingots in the workshop space to cooling inside the furnace with forced delivery of the coolant, which became possible due to use of modern low inertia materials as the lining of the furnace - ceramic fiber.

The known information on heat engineering processes coming on convective heat exchange of solid surfaces with gaseous medium flow is analyzed in [2,3]; the existing methods for metal AC processes calculation are considered in [4]. They do not allow to get all the necessary information about influence of technological and design parameters on all the characteristics of AC operation.

Also the problems associated with the lack of criterial equations describing convective heat transfer on metal $\mathrm{AC}$ in real conditions are identified. In some cases it leads to inability to determine directly the required amount of cooling air for attaining specified cooling parameters. The aim of this paper is to investigate the influence of technological and design parameters on the duration of the metal AC operation, as well as disclosure of heat engineering processes on metal AC regularities.

\section{Materials and Methods}

To solve the research problems, mathematical model of metal AC process in furnaces is used, based on solving the differential non-stationary heat conductivity equation [5]. Taking into account that ingots butt-ends surfaces area is many times smaller than the area of the side surface, the differential equation of non-stationary heat conduction in the onedimensional formulation is chosen to describe the thermal state of the ingots. A similar approach has been chosen to describe the thermal state of the lining in connection with a significantly smaller one of the geometric dimensions (thickness) as compared with two others (length, height).

The scheme for setting uniqueness conditions for ingots and lining is worked out, including geometric, initial, boundary conditions and setting the dependence on temperature of media and materials participating in heat transfer heat engineering characteristics. Geometric conditions of heat transfer for metal and lining are presented in one-dimensional form in Figure 1: $\mathrm{r}$ is an arbitrary radius in the ingot cross section; $\mathrm{S}$ is the thickness of the lining; $\mathrm{Y}$ - selected positive direction on the coordinate axis
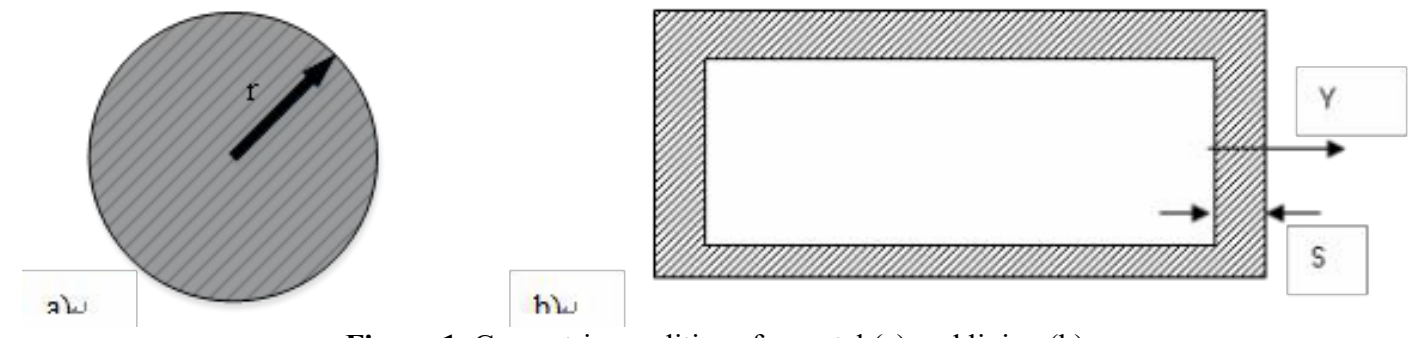

Figure 1. Geometric conditions for metal (a) and lining (b)

The differential equation of non-stationary heat conduction in the one-dimensional formulation in the polar coordinate system for metal is written as follows:

$$
\frac{\partial \mathrm{t}}{\partial \tau}=\frac{\lambda(\mathrm{t})}{\mathrm{c}(\mathrm{t}) \rho}\left(\frac{\partial^{2} \mathrm{t}}{\partial \mathrm{r}^{2}}+\frac{1}{\mathrm{r}} \cdot \frac{\partial \mathrm{t}}{\partial \mathrm{t}}\right)
$$

where:

$\lambda(\mathrm{t})$ is the coefficient of thermal conductivity, $\mathrm{W} /(\mathrm{m} \cdot \mathrm{K})$;

$\mathrm{c}(\mathrm{t})$ is the heat capacity, $\mathrm{J} /(\mathrm{kg} \cdot \mathrm{K})$;

$\rho$ is the density, $\mathrm{kg} / \mathrm{m} 3$. 
For lining the same differential equation in a Cartesian coordinate system is used. When specifying the boundary conditions for heat transfer, the following elements of the thermal interaction are taken into account: convective heat exchange between metal and air; convective heat exchange between lining and air; radiant heat exchange between metal and lining. The boundary conditions of heat transfer for metal and lining are set as followed.

Metal:

$$
\left\{\begin{array}{c}
\mathrm{r}=\mathrm{r}_{1}-\lambda \frac{\partial \mathrm{t}}{\partial \mathrm{r}}=\alpha_{\mathrm{conv}}^{\mathrm{m}}\left(\mathrm{t}_{\mathrm{m}}-\mathrm{t}_{\mathrm{a}}\right)+\alpha_{\mathrm{rad}}^{\mathrm{m}-1}\left(\mathrm{t}_{\mathrm{m}}-\mathrm{t}_{1}\right) \\
\mathrm{r}=0 \cdot \lambda \frac{\partial \mathrm{t}}{\partial \mathrm{r}}=0
\end{array}\right.
$$

Lining:

$$
\left\{\begin{array}{c}
\mathrm{y}=0-\lambda \frac{\partial \mathrm{t}}{\partial \mathrm{y}}=\alpha_{\text {conv }}^{1}\left(\mathrm{t}_{1}-\mathrm{t}_{\mathrm{f}}\right)-\left[\alpha_{\text {rad }}^{\mathrm{m}-1}\left(\mathrm{t}_{\mathrm{m}}-\mathrm{t}_{1}\right)\right] \frac{\mathrm{F}_{\mathrm{m}}}{\mathrm{F}_{1}} \\
\mathrm{y}=\mathrm{s}-\lambda \frac{\partial \mathrm{t}}{\partial \mathrm{y}}=\alpha_{\text {sur }}\left(\mathrm{t}_{1}^{\text {out }}-\mathrm{t}_{\text {sur }}\right)
\end{array}\right.
$$

where:

$\alpha_{\text {conv }}^{m}$ - convective heat transfer coefficient from metal to cooling air, $\mathrm{W} /\left(\mathrm{m}^{2} \cdot \mathrm{K}\right)$;

$\mathrm{t}_{\mathrm{m}}$ - temperature of the cooled metal surface, ${ }^{\circ} \mathrm{C}$;

$\mathrm{t}_{\mathrm{a}}$ - temperature of the air supplied to the metal surface, ${ }^{\circ} \mathrm{C}$;

$\alpha_{\text {rad }}^{m-1}$ - radiant heat transfer coefficient from metal to lining, $\mathrm{W} /\left(\mathrm{m}^{2} \cdot \mathrm{K}\right)$;

$\mathrm{t}_{1}$ - temperature of the inner surface of the lining, ${ }^{\circ} \mathrm{C}$;

$\alpha_{\text {conv }}^{1}$ - convective heat transfer coefficient from the lining to the cooling air in the furnace, $\mathrm{W} /\left(\mathrm{m}^{2} \cdot \mathrm{K}\right)$;

$\mathrm{t}_{\mathrm{f}}$ - average air temperature in the furnace chamber, ${ }^{\circ} \mathrm{C}$;

$\mathrm{F}_{\mathrm{m}}$ - metal surface area, $\mathrm{m}^{2}$;

$\mathrm{F}_{1}$ - lining surface area, $\mathrm{m}^{2}$.

$\alpha_{\text {sur }}$ - coefficient of convective heat transfer from the outer surface of the lining to the atmosphere, $\mathrm{W} /\left(\mathrm{m}^{2} \cdot \mathrm{K}\right)$;

$t_{1}^{\text {out }}$ - outside lining temperature, ${ }^{\circ} \mathrm{C}$;

$t_{\text {sur }}$ - ambient air temperature, ${ }^{\circ} \mathrm{C}$;

The value of $t_{a}$ is determined on the basis of turbulent jets theory, taking into account the mixing of fresh air supplied for cooling with hot air in the furnace chamber having temperature $t_{f}$.

If some elements of lining are made of different materials, then for each of them the differential equation of nonstationary heat conductivity with the corresponding uniqueness conditions is solved separately. When formulating the uniqueness conditions for metal, it is taken into account that there is a radiant heat exchange with various elements of the lining. In the same manner radiant heat exchange between different elements of the lining is considered. In this case, when calculating the reduced radiation coefficient in the metal-lining system, the corresponding angular coefficients, the degree of blackness of the metal and elements of inner surfaces of the lining are taken into account.

The coefficient of convective heat transfer from metal can be estimated by means of known criterion equations characterizing the simplest hydrodynamic interaction schemes. But in connection with the fact that the real schemes of air flow leakage on the metal differ from the simplest theoretical schemes, the necessity of experimental data using that better suits real conditions is substantiated. In this study for setting the values of the convective heat transfer coefficients for various schemes of hydrodynamic interaction of air and metal criterion equations proposed in ${ }^{[6]}$ are used:

$$
N u=0.14 \cdot \operatorname{Re}^{0.62} \cdot \operatorname{Pr}^{0.36} \cdot\left(\frac{P r_{m}}{P r_{w}}\right)^{0.25} ; N u=1.49 \cdot R e^{0.5} \cdot P r_{m}^{0.36} \cdot\left(\frac{P r_{m}}{P r_{w}}\right)^{0.25} ;
$$

where:

$\mathrm{Nu}$ - Nusselt number, ratio of convective and conductive heat transfer intensities across the boundary;

Re - Reynolds number, ratio of inertial forces to viscous forces;

$\operatorname{Pr}$ - Prandtl number, ratio of kinematic viscosity to thermal diffusivity; 
m, w - indexes that signalize that Pr number is taken at temperature of heat transfer medium bulk or at solid wall surface temperature respectively.

These equations describe convective heat exchange for cases when gaseous medium is blown onto bodies of cubic and cylindrical shape respectively. They were obtained experimentally on a physical model, geometrically similar to a typical chamber furnace for heat treatment.

Confirmation of adequacy of used mathematical model was carried out as a result of comparison of the experimental curves describing temperature change on the ingots surface in the certification heat treatment mode in an industrial furnace delivered by CJSC "Termostal" for CJSC "Yurginsky Machine Plant" with the results of mathematical modeling. The thermometric experiment was carried out during heat treatment of 12 cylindrical ingots with diameters from 360 to $470 \mathrm{~mm}$ and lengths from 3 to 6.82 meters with a total mass of $81,358 \mathrm{~kg}$. Comparison of the metal surface temperature change obtained with the mathematical model with the data from the thermogram of the AC process in temperature range $900-300{ }^{\circ} \mathrm{C}$ proved that their difference does not exceed $5 \%$.

\section{Ethics Statement}

In the presented form, the paper was not previously published neither whole nor in parts. Some of the results presented in this paper were previously offered to the scientific community. The need of this work preparing was substantiated due to reasonability of metal air cooling in furnaces heat exchange processes study results complex presentation.

\section{Results}

Using the mathematical model, the influence of the lining parameters on the duration AC process was studied.

Three conventional types of lining were distinguished:

- $\quad$ the entire lining is made of chamotte fireclay bricks;

- $\quad$ the furnace hearth is made of chamotte bricks, the walls and roof are covered from inside with ceramic fiber;

- $\quad$ conceptual type - the use of ceramic fibers on all internal surfaces of the furnace, including hearth.

Furnace is $12 \mathrm{~m}$ in length, $6 \mathrm{~m}$ in width and $4 \mathrm{~m}$ in height. In considered example during cooling, metal surface temperature reduces from 650 to $450{ }^{\circ} \mathrm{C}$. For all considered lining types three kinds of loads were considered: two, four and six ingots of cylindrical shape, 1 meter in diameter, 6 meters in length. Four air flow rates were chosen: 5, 10, 15, 20 thousand $\mathrm{m}^{3} / \mathrm{h}$. The results of the study for four blanks are present on ${ }^{[7]}$ and shown in Figure 2.

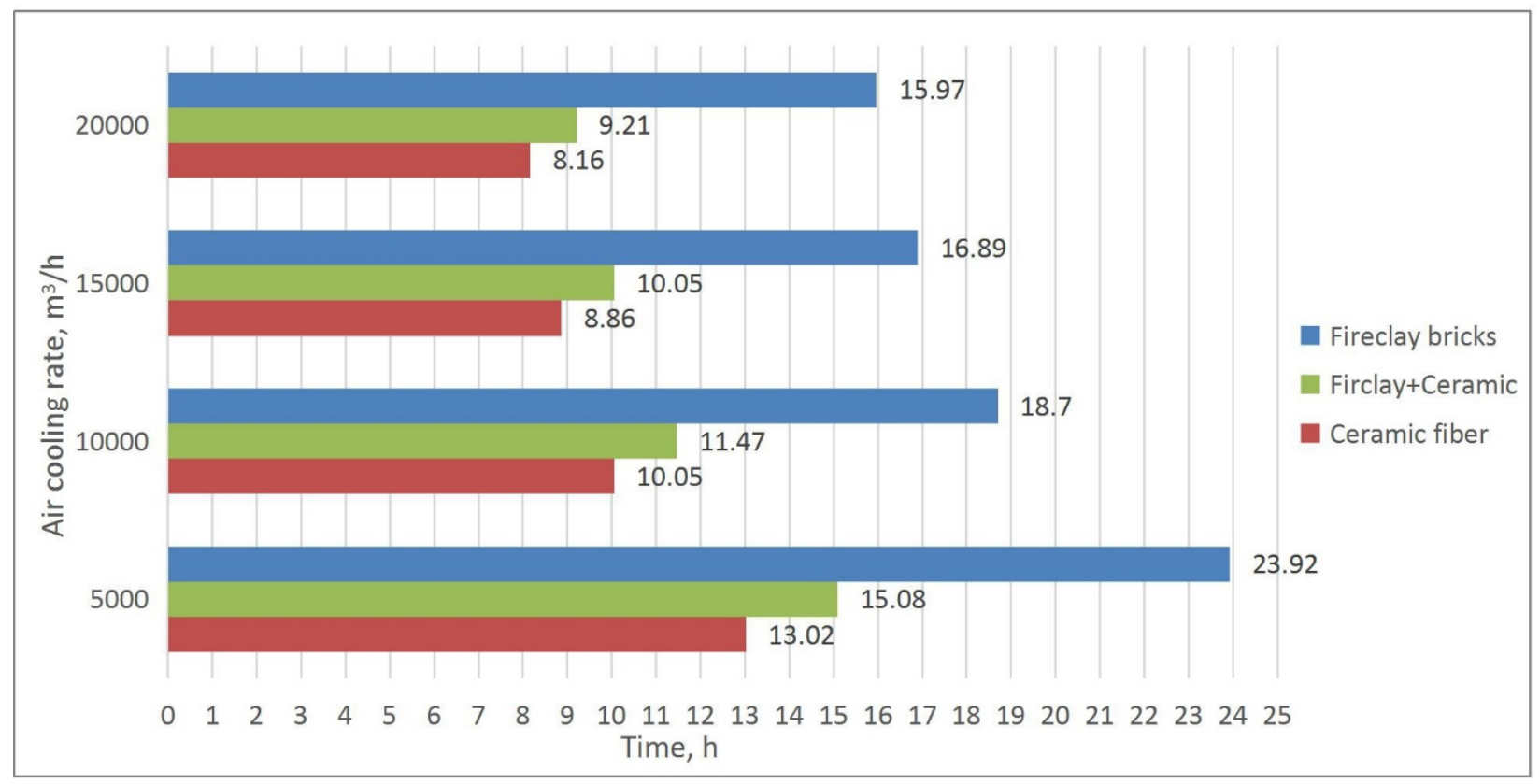

Figure 2. Comparison of AC duration with different lining designs 
$\mathrm{AC}$ acceleration is achieved with the use of ceramic fibers by $31-45 \%$ (when comparing the first and second variants of the lining design) and 44-52\% when comparing the first and the third variants depending on air flow rates and amount of ingots.

The mechanism of heat removal from metal has been investigated, with the aim of establishing the fraction of radiant and convective components. For a typical arrangement of the furnace - hearth of fireclay bricks and ceramic fiber on the walls and roof, the proportion of the convective component for different cooling air flow rates is shown in Figure 3a. For the conceptual lining - completely consisting of ceramic fibers - the fraction of the convective component is shown in Figure 3b.

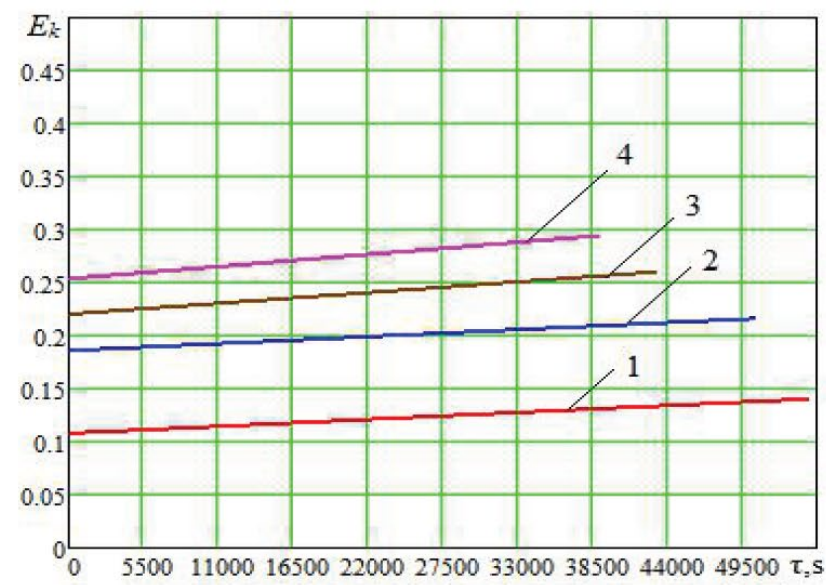

(a)

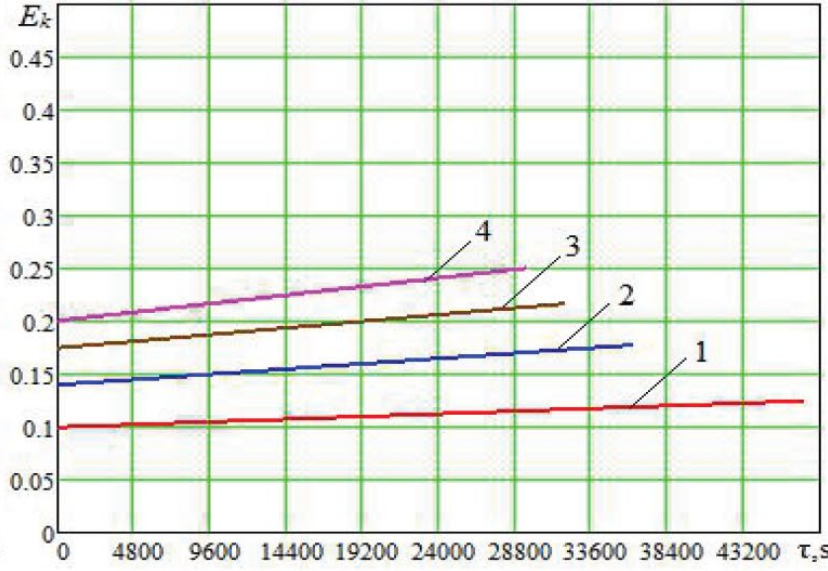

(b)

Figure 3. The fraction of convective component in the total amount of heat removed for different air flow rates (curves 1-5000; 2-10000; 3-15000; 4-20000 $\mathrm{m}^{3} / \mathrm{h}$ )

With the help of a mathematical model, the temperature variation of different parts of the combined lining during the AC process was estimated. For example, Figure 4 shows the change in the temperature field of the fireclay brick (a) and ceramic fiber (b) parts of the lining when four cylindrical ingots is cooled in a chamber furnace with a flow rate of $15000 \mathrm{~m} 3 / \mathrm{h}$. It can be seen that the fireclay brick part of the lining cooled slower and is generally hotter (on the surface and along thickness) than the ceramic fiber part. Due to that radiant heat transfer between the metal and the fireclay brick part of lining goes less intensively.

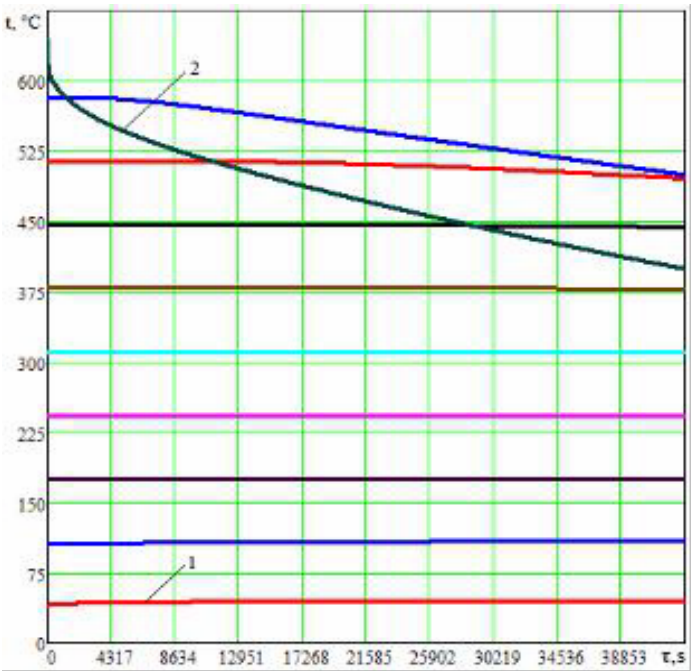

(a)

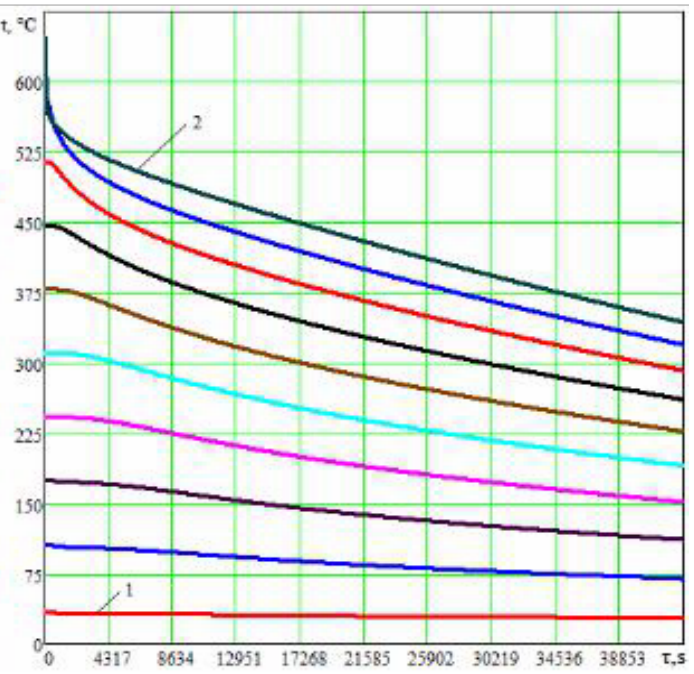

(b)

Figure 4. Temperature variation of different parts of the lining by thickness

1 - temperatures of the outer part of the lining; 2 - temperatures of the inside of the lining;

(a) the temperature field of the fireclay brick lining; (b) the temperature field of the ceramic fiber lining 


\section{Discussion}

The scientific ideas on the mechanism of heat removal in the case of metal AC in the furnace have been developed, by establishing the proportion of heat that is directly removed from the surface of the metal by convection and amounts to $10-30 \%$, depending on the mass of the furnace load and the flow rate of cooling air. The rest of the heat is transferred by radiation to the surface of the lining and removed from it by cooling air.

In figure 4, it can be seen that the fireclay brick part of the lining is cooled slower and is generally hotter (on the surface and along thickness) than the ceramic fiber part. Due to that radiant heat transfer between the metal and the fireclay brick part of lining goes less intensively.

\section{Conclusion}

The influence of the lining parameters on AC process in furnace is studied. The acceleration of this operation can be achieved by using low-inertia lining materials instead of fireclay bricks and it can reach $43-50 \%$, depending on the coolant consumption. When using fireclay brick at the hearth and ceramic-fiber covering of walls and roof, the acceleration is $30-41 \%$, depending on the same parameters.

The fraction of the radiant and convective component is analyzed when the metal is cooled in the furnace at various parameters of the load and lining and air flow rates, so that a mechanism for removing heat from the metal is established. It is proved that the share of the convective component is in the range of $10-30 \%$, depending on the mass of the furnace load and the flow rate of cooling air.

With the help of mathematical model, it has been established that fireclay brick part of the furnace lining is cooled slower and so it is hotter than ceramic fiber part, which leads to slowing radiant heat exchange between metal and lining.

\section{References}

1. Sanghoon Noh, Byoung-Kwon Choi, Chang-Hee Han, Suk Hoon Kang, Jinsung Jang, Yong-Hwan Jeong, Tae Kyu Kim, Effects of heat treatments on microstructures and mechanical properties of dual phase ods steels for high temperature strength, Nuclear Engineering and Technology, 2013, Vol. 45 (6), pp. 821-826

2. Seung Chul Baik, Ohjoon Kwon, Seong-Jun Park, Byung-Hee Hong, Kyu Hwan Oh, Analysis of heat transfer in hot rolled coils for optimum condition of forced cooling, Metals and Materials, 1999, Vol. 5, Issue 4, pp. 369-375

3. Fabio Gori, L. Bossi, On the cooling effect of an air jet along the surface of a cylinder, International Communications in Heat and Mass Transfer, 2000, Vol. 27(5), pp. 667-676

4. Гусовский В.Л. Методики расчета нагревательных и термических печей: учебно-справочное издание / В.Л. Гусовский, А.Е. Лифшиц. - М.: Теплотехник, 2004. - 400 c. (Gusovskij V.L. Metodiki rascheta nagrevatel'nyh i termicheskih pechej: uchebno-spravochnoe izdanie / V.L. Gusovskij, A.E. Lifshic. M.: Teplotehnik, 2004. - 400s).

5. Biryukov A.B., Voloshin A.I., Gnitiev P.A., Mathematical model for studying of metal air-cooling process in furnaces, Steel in Translation, 2015, Vol. 45(7), pp. 534-538

6. Biryukov A.B., Gnitiev P.A., Experimental investigation of convective heat exchange in chamber furnaces at heat treatment of cylindrical solids, Thermophysics and Aeromechanics, 2016, Vol. 23 (3), pp. 467-472

7. Biryukov A.B., Gnitiev P.A., Investigation of lining parameters impact onto metal air-cooling process in chamber furnace, Izvestiya Vysshikh Uchebnykh Zavedenij. Chernaya Metallurgiya, 2016, Vol. 59(11), pp. 759-763 